\title{
Research Paper \\ Analysis of Rural Area Resilience Against Earthquake; Case Study: Shirvan District (Boroujerd County)
}

\author{
*Seyed Hedayatollah Noori ${ }^{1}$, Farkhondeh Sepahvand ${ }^{2}$
}

1. Associate Professor, Department of Geography and Rural Planning, Faculty of Geographic Sciences and Planning, University of Isfahan, Isfahan, Iran. 2. PhD Candidate, Department of Geography and Rural Planning, Faculty of Geographic Sciences and Planning, University of Isfahan, Isfahan, Iran.

Citation: Noori, S. H., \& Sepahvand, F. (2016). Analysis of Rural Area Resilience Against Earthquake; Case Study: Shirvan District (Boroujerd County). Journal of Rural Research, 7(2), 272-285.

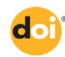

Received: 21 Feb 2016

Accepted: 17 May 2016

Key words:

Natural disasters

Resilience, Local households, Earthquake, Shirvan district

\begin{abstract}
Earthquake is one of the natural disasters that cause irreparable damages to human settlements. Therefore, in order to reduce its impact, the resilience approach has been proposed. It is believed that by having the knowledge of resiliency and proper planning, the damaging effects of such natural disasters can be reduced significantly. Thus, in this descriptive-analytic study, we identify and analyze the resiliency of villages in the district of Shirvan against earthquakes. In order to collect the required data, both documentary and field (questionnaire) methods were employed. Questionnaires were used to collect data in nine villages, and statistical methods were used to analyze the collected data. The analysis units were the heads of households living in sample villages. Based on Cochran's method, 260 administrators were randomly selected. The results showed that the resiliency condition against earthquakes in the sample villages was lower than the average level; however, there was a significant difference in the resiliency levels among the sample villages. In addition, among the economic, social, infrastructural, and social capital aspects in rural areas, the social capital was found to have the most contribution and effect on the resilience of rural settlements.
\end{abstract}

\section{Extended Abstract}

\section{Introduction}

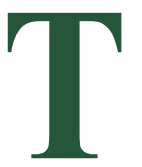

he occurrence of natural disasters is a prevailing phenomenon associated with both severe physical and psychic damages. Therefore, scientists, scholars, and planners have attempted to reduce the damages caused by such disasters via approaching different patterns and putting suitable plans into place. One of these approaches is disaster resilience. As many researchers have suggested, resilience is one of the most important subjects in the way to sustainability. Resilience has been introduced as a way for strengthening communities in view of their potentials, and it has been formed various definitions, indices, approaches and measure models around it. Local resilience regarding disaster type means that local society would be able to stand against severe natural disasters without compromising its destructive losses and damages or losing production power or life quality or receiving huge help out of their society.

Lorestan Province located on the Zagros seismic fault counts as one of the seismic areas of Iran. In this Province, the Shirvan district (Boroujerd County) is a seismic area

\section{* Corresponding Author:}

Seyed Hedayatollah Noori, PhD

Address: Department of Geography and Rural Planning, Faculty of Geographic \& Planning Science, University of Isfahan, Isfahan, Iran.

Tel: +98 (913) 3150545

E-mail: hedayatnouri@gmail.com 
because its location on the Silakhor fault. Quake occurrence has repeatedly left harmful effects on the residents, particularly rural areas that are more vulnerable due to their spatial conditions. Therefore, this study tries to answer the following questions: 1) What is the level of disaster resilience of these villages? 2) Are there any significant differences between these sample villages in terms of the level of their disaster resilience against earthquakes? 3) Is there any significant relationship between resilience against earthquake and economic, social and cultural status and infrastructures and social capital? and 4) Which one of these aspects has the most effect on the level of resilience?

\section{Methodology}

Our study is an applied study in terms of its goal, and its method of accomplishment is descriptive and analytic. To collect the required information, we used both library and field (questionnaire) methods. Our study field was Shirvan district (central part), which is located at Broujerd County (Lorestan Province). Nine villages in this district were less than one kilometer away from the seismic fault (including Darb-Astaneh, Papulak, Chegenikesh, Dinarabad, Ghaleh shekar, Khan amir, Dartoot, Down Sartappe and Oodmola), and we used all of them as our statistical population. Using Cochran method, we selected 260 out of 798 households in these 9 villages as our statistical sample.

In the study of resilience against earthquake, we considered economic, social, cultural, and infrastructural aspects as our dependent variables and social capital as our independent variable. The level of resilience, as our dependent variable, has been studied using 5 indicators including preparation level in case of earthquake occurrence, psychic status to admit earthquake, ability to keep morale in case of quake occurrence, ability to help others in case of quake occurrence, and ability to prepare new jobs in case of quake and losing current jobs. Eight indicators were used to measure economic status, 6 indicators for social and cultural status, 9 indicators for infrastructural status of villages, and 6 indicators were used for measuring social capital. To analyze our data and achieve our goals of the study, we used descriptive and inferential statistics (one-sample t-test, oneway ANOVA, Pearson correlation, regression method).

\section{Results}

The study and analysis of the indicators related to resilience level against earthquake show that the most mean value is for the indicator of ability to help others in case of quake and the least mean value corresponds to the indicator of preparation level in case of quake occurrence. The study of economic status in terms of resilience in our sample vil- lages showed that the most and the least mean value correspond to the indicators of satisfaction about buildings' robustness and not having a fluctuating occupational dependence, respectively.

Regarding the social and cultural status of villages, it has been determined that the indicator of satisfaction from public transportation and the indicator of satisfaction from home insurances have, respectively, the most and the least mean value. The analysis of indicators related to measuring infrastructural status against quake also shows that among its related indicators, the most mean value corresponds to the indicator of villages enjoying electricity and power infrastructures, and the least mean value corresponds to the indicator of access to firefighting facilities. Finally, the study of social capital in the villages suggests that the most and the least mean values correspond to the indicators of persistence in village and communication between communities, private sector, and local officials, respectively.

\section{Discussion}

Natural disasters are considered as dangers repetitively borne by nature. So, nowadays there are different managerial methods to stand against disasters and reduce their destructive effects. In this regard, resilience approach has been recently mentioned. Resilience approach in line with strengthening communities' abilities and mitigating vulnerability leads to the improvement of rural lives' resilience.

\section{Conclusion}

In this study, we considered resilience status of rural communities of Shirvan district located in Boroujerd County (Lorestan Province). Our results showed that resilience status in the sample villages is in the lower level than the normal level, but among the sample villages, there is a significant difference in terms of resilience against earthquake. In this study, we also addressed economic, social and cultural, infrastructural status and social capital in these villages, and the related results showed that the villages have a higher level in all four mentioned aspects. Our statistical analyses also suggest that there is a direct statistically significant relationship between the level of resilience against earthquake, and the four aspects. In other words, an improvement in the status of these four aspects might lead to improving resilience level. It has also determined that the most correlation value corresponds to the social capital aspect, and the least correlation value corresponds to the infrastructural status of these villages. 


\title{
تحليل تابآورى سكونتگًاههاى روستايى دربرابر مخاطرات طبيعى با ثأكيد بر زلزله (مورد مطالعه: دهستان شيروانِ شهرستان بروجران
}

\author{
"سيدهدايتالله نورى'، فرخنده سيهوندץ" \\ 1 - دانشيار، كروه جغرافياو برنامهريزى روستايى، دانشكده علوم جغرافيايى و برنامهريزي، دانشكاه اصفهان، اصفهان، ايران.

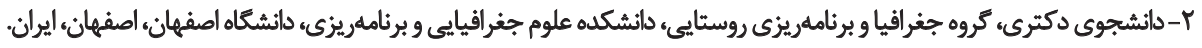

\begin{abstract}
حكين

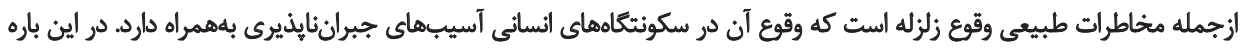

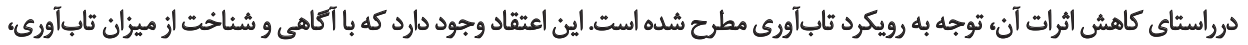

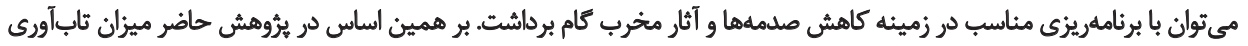

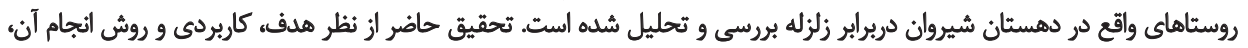

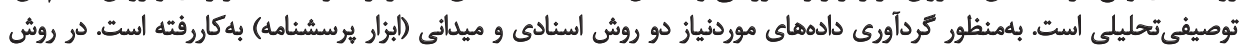

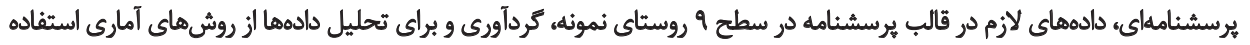

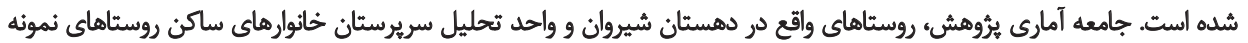

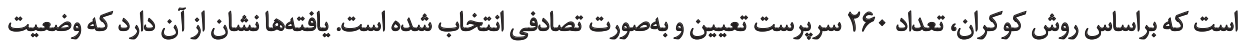

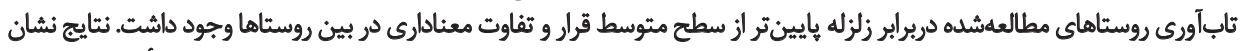

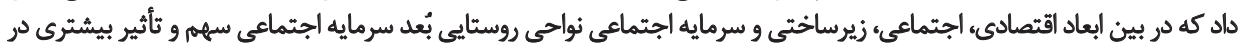

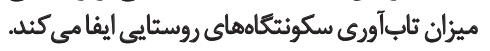

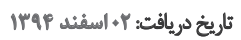

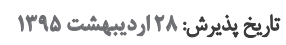

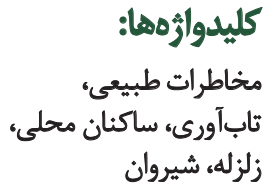

زلزله، شيروان

تاب آورى دربرابر مخاطرات طبيعى است. مفهوم تابآورى ارمغان

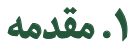

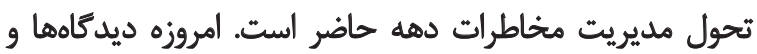

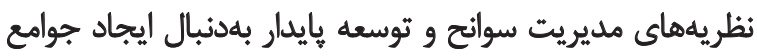

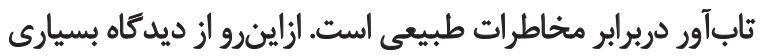

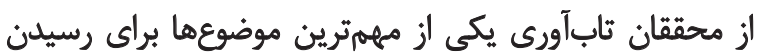

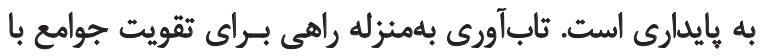

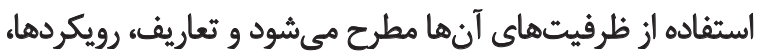

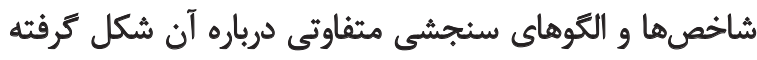
است (Sadeghloo, \& Sojasi, 2015).

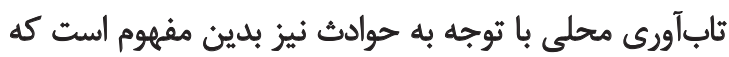

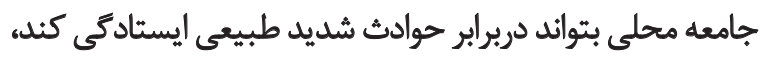

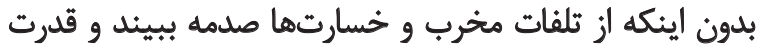

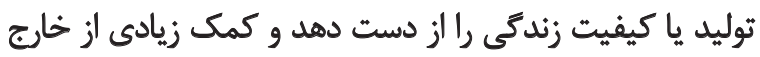

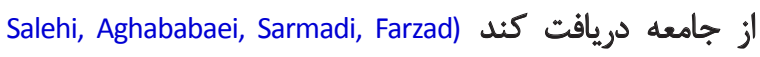

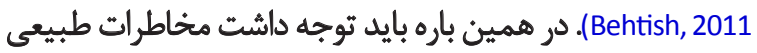

از طريق آسيبهايى از اين دست تابآورى را كاهش مى بدهدا:

امروزه وقوع مخاطرات طبيعى بلعنوان يديدهاى تكراريذير محسوب

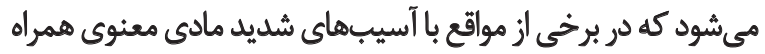

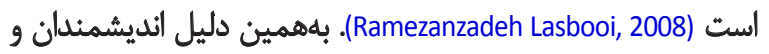

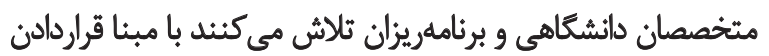

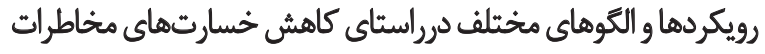

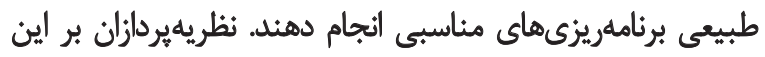

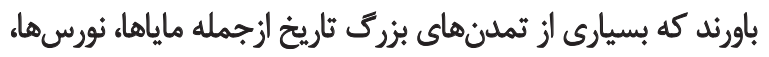

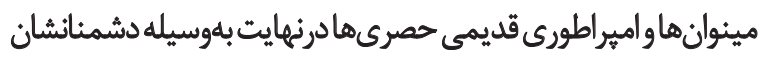

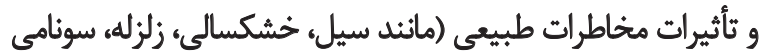

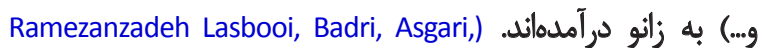

.(Salmani, Ghadiri Masom, 2013

امروزهدولتها براى كاهش اثرات مخاطرات طبيعى، راهبردهاى رئي

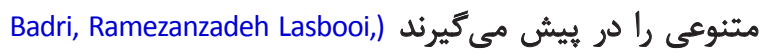
Asgari, Ghadiri Masoum, Salmani, 2013 يكي إنى از اين رويكردها، 
روستاهاى بررسىشده وجود دارد؟؟ f. كداميك از ابعاد بر ميزان تابآورى جوامع محلى تأثير

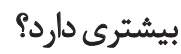

\section{T. مرورى بر ادبيات موضوع}

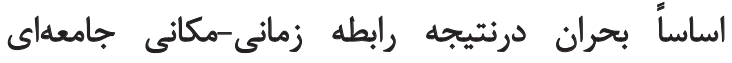

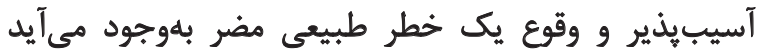
مخاطرات هنغًامى تبديل به فاجعه بهائ (Gaillard \& Texier, 2010).

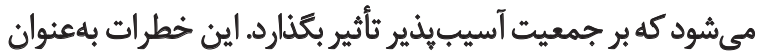

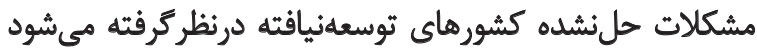

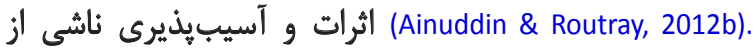

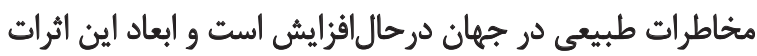

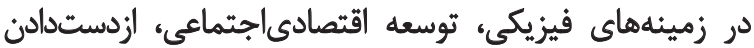

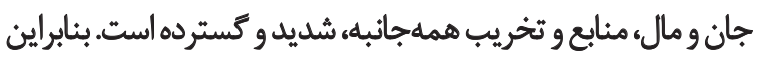

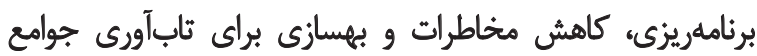

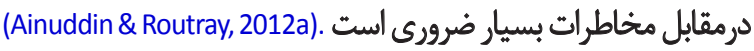

ثلاش براى كاهش آسيبيذيرى نشان مى دهد كه بايد راهبردى

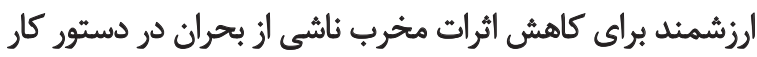
سياستهاي اجتماعى روز قرار كيرد (Paten \& Johnston, 2001).

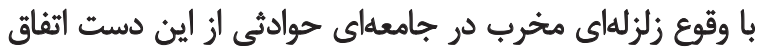

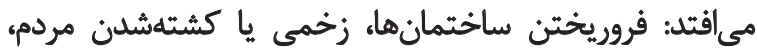

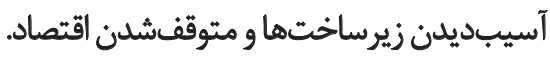

اثرات ناشى از زلزله بر جوامع مىتواند بسيار ويرانكر باشد.

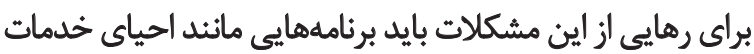

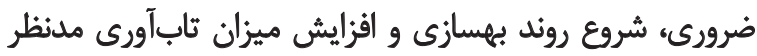

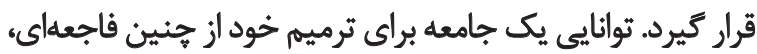

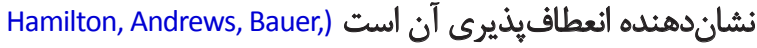

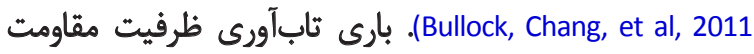

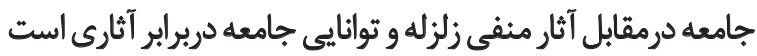

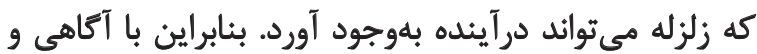

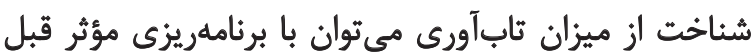

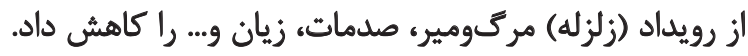

.(Bruneau, Chang, Eguchi, Lee, O’Rourke, 2003)

شايان ذكر است كه امروزه تحليل و افزايش تابآورى دربرابر

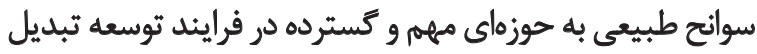

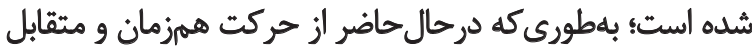

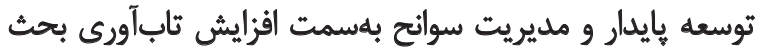

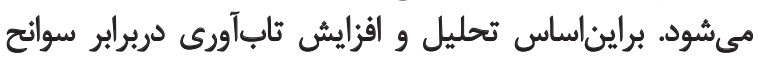

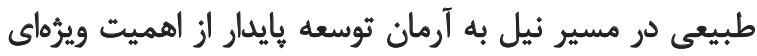

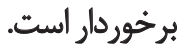

وازه تابآورى اغلب به مفهوم البازگشت به كذشتهه به كار مىرود
1. آسيبهاي فيزيكى: شامل آسيبهاى واردشده به كاربرىهاى تاري مسكونى، تجارى، مدارس، تجهيزات و و تأسيسات؛ r. آسيبهاي اقتصادى: شامل ازبينرفتن اشتغال، تعليق تجارت، هزينههاى تعمير و بازسازى؛ ك. آسيبهاى اجتماعى: شامل تأثير بر افرادى كه به كمكهاي دارويي و سريناه نياز دارند (Sharifnia, 2012).

ايران باتوجه به موقعيت جغرافيايى وقرار مرفتن بر كمربيند زلزله.

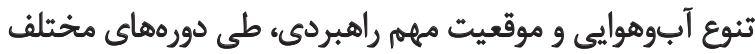

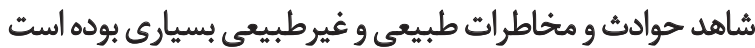

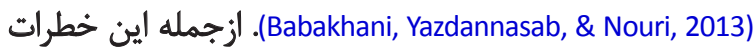

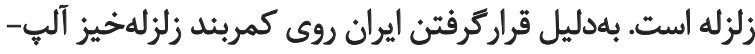

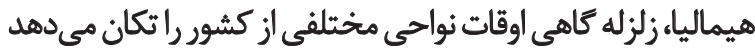

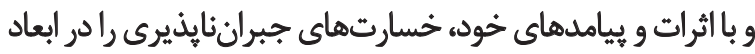

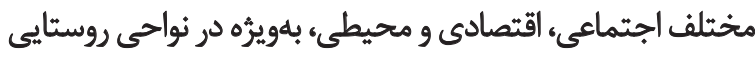

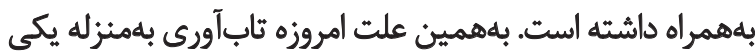

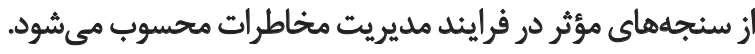

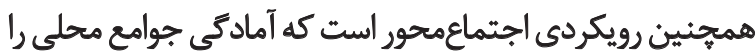

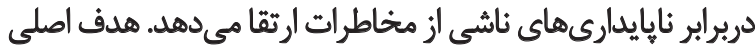

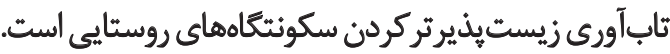
استان لرستان بهعلت قراركرفتن بر منطقه لرزهاى زمينساخت

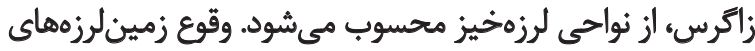

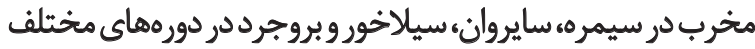

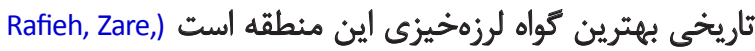

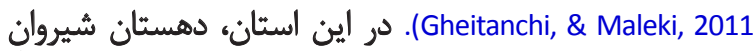

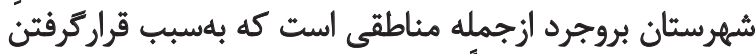

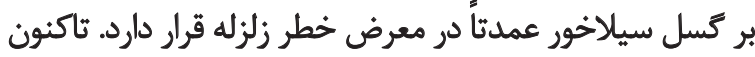

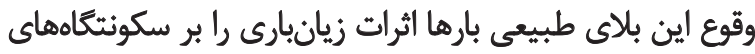

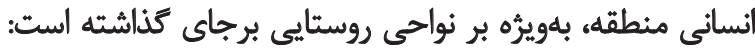

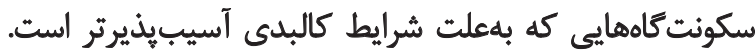

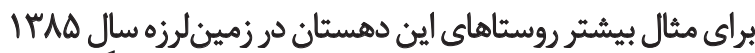

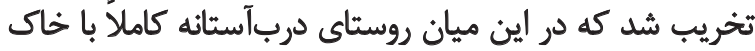

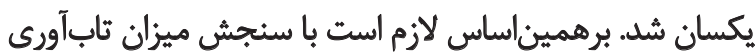

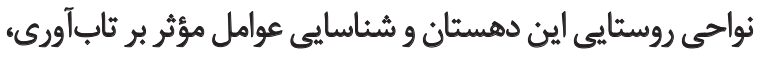

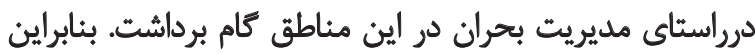
يروهش حاضر براى ياسختويى به سؤالات زير انجام شده است: 1. ميزان ثابآورى روستاهاى مطالعهشده دربرابر وقوع زلزله در جه سطحى قرار دارد؟؟ ז. در بين روستاهاى نمونه از نظر ميزان تابآورى دربرابر وقوع

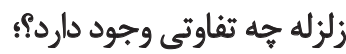

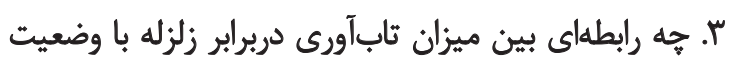
اقتصادى، اجتماعىفرهنكى، زيرساختى و سرمايه اجتماني درئي 


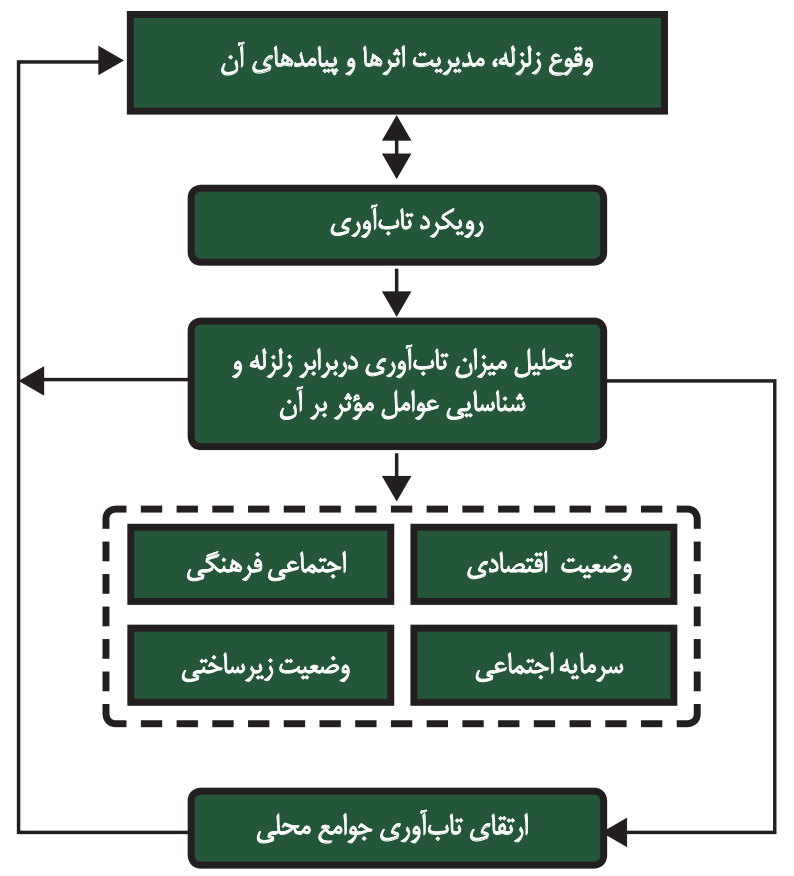

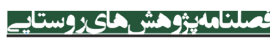

$$
\text { تصوير ا. الكوى مفهومى تحقيق. }
$$

ا ـ مخاطرات مئاسب و مرتبط شناسايى ودرك ميشود؛ r. جوامع درخطر مى دانند كه جهموقع خطر زودهنگام است؛ ". افراد درخطر از هخاطرات درامان هستئك

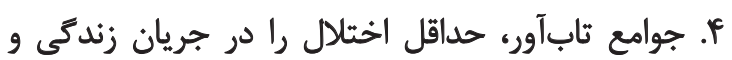

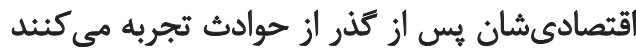

.(Salehi, Aghababaei, Sarmadi, \& Farzad Behtish, 2011)

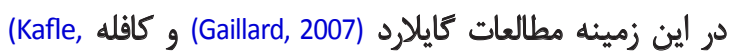

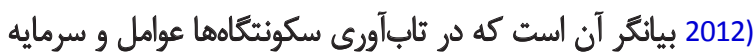

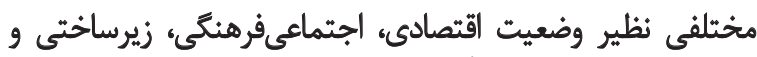

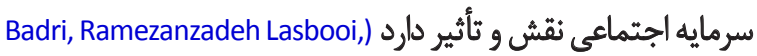
.(Asgari, Ghadiri Masoum, \& Salmani, 2013

در يك نتيجهيرى كلى براساس آنجه مطرح شد، بايد اذعان

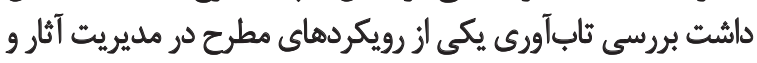

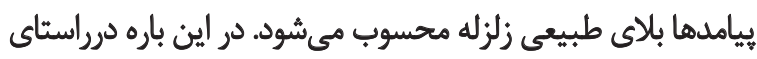

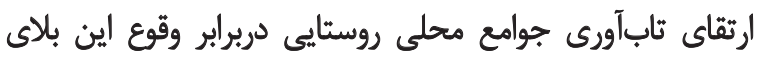

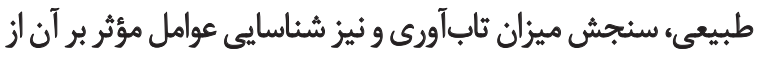

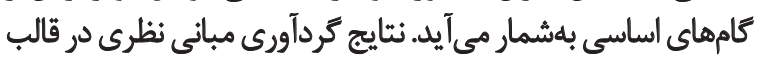

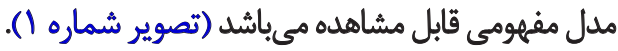
"ا. روششناسى تحقيق هدف تحقيق حاضر از نوع كاربردى و روش انجام آن

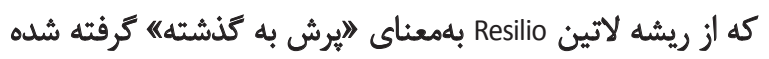

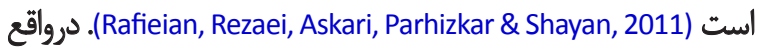

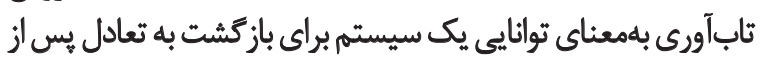

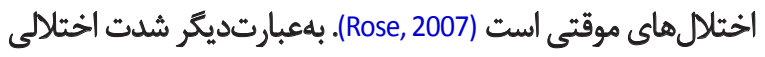

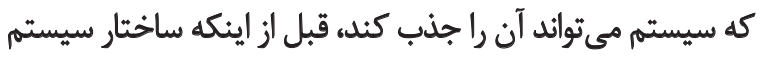

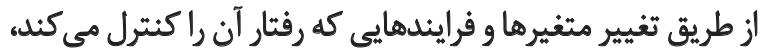

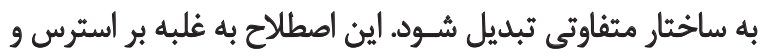
ناملايمتها اشاره مي كند (Rutter, 1999).

ثاب آورى ريشه در مطالعات طبيعى زيستمحيطى دارئه دارد.

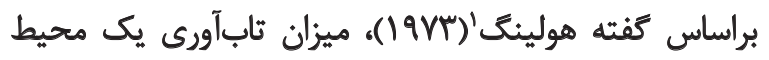

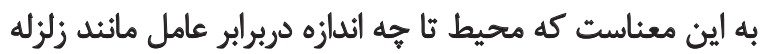

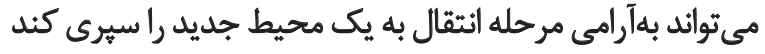
و به محيطى يايدار تبديل شود (Petak, 2002).

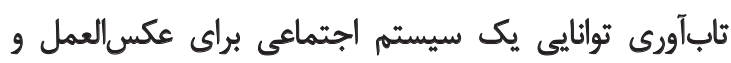

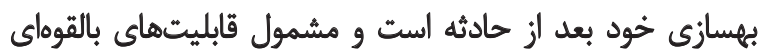

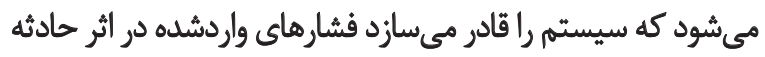

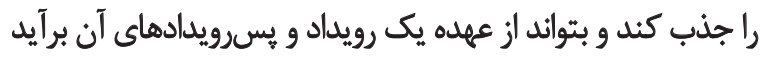

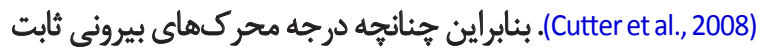

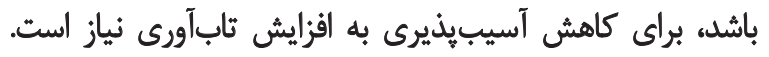

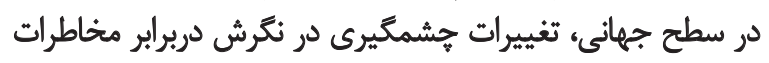

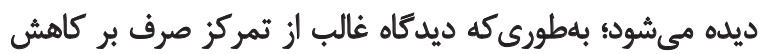

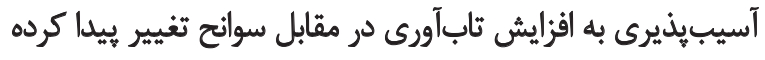
است (Eftekhari, Mosavi, Poortaheri, \& Farajzadeh, 2014).

بايد توجه داشت كه برنامههاي كاهش مخاطرات، بايد

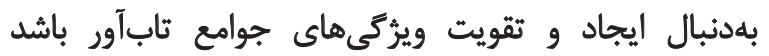

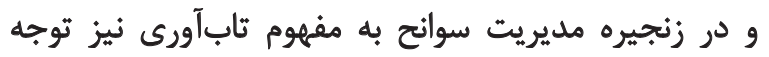

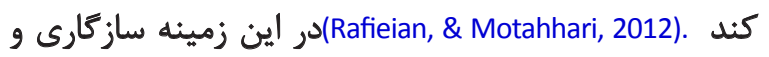

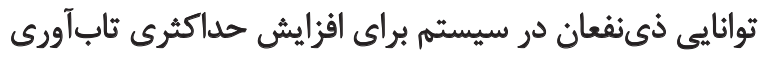

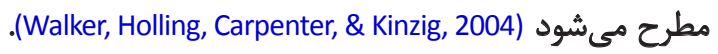

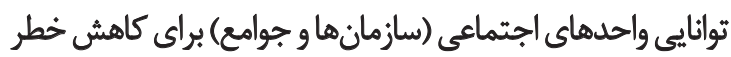

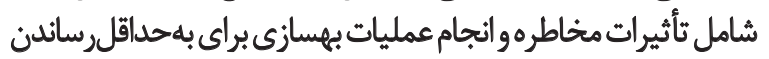

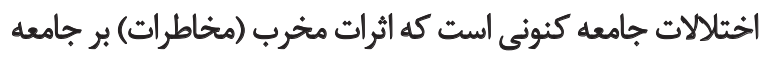

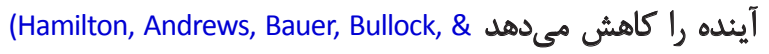

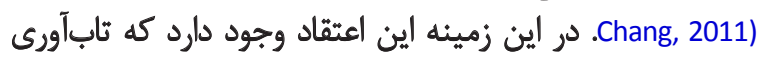

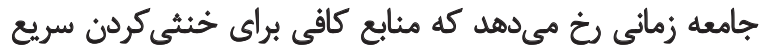

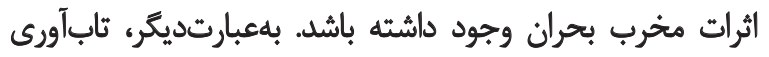

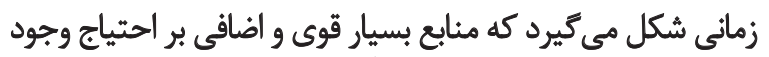

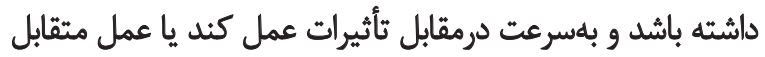
نشان دهد (Ride, 2011). در كميته كاهش مخاطرات (SDR, 2005) ويرّكى هاى جوامع 


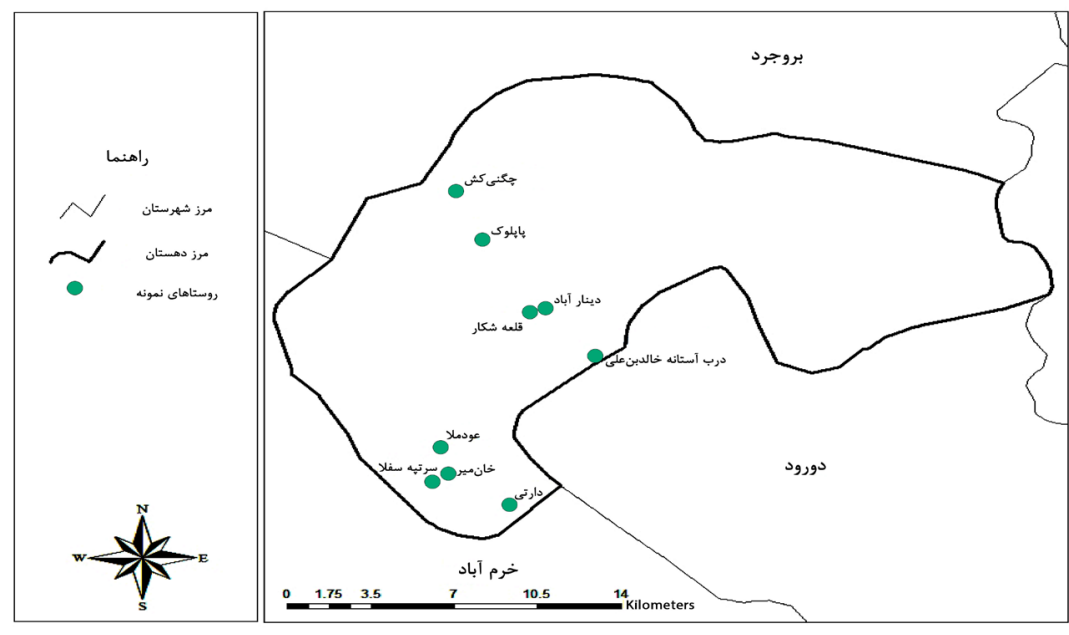

:

تصوير Y. موقعيت محدوده و روستاهاي نمونئه.

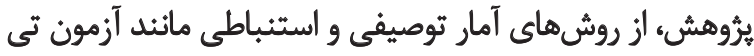

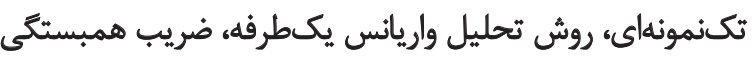
بيرسون و روش ركرسيون استفاده شده است.

f أ ياثته ها

بررسى ويرُكى هاى فردى ياسخ تويان نشان مى دهد از مجموع

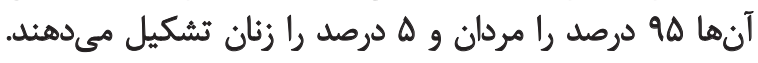

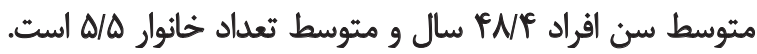

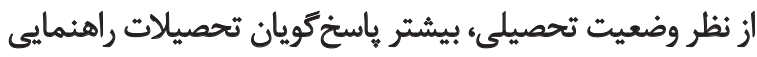

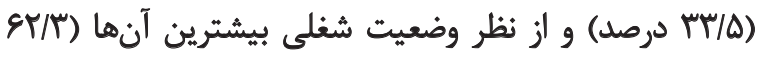

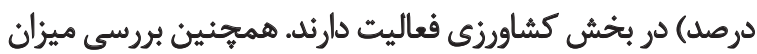

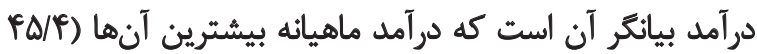

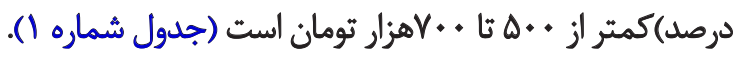

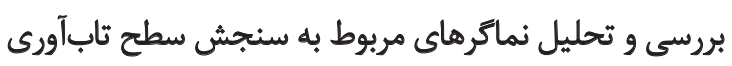

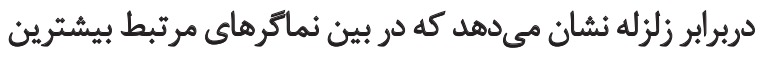

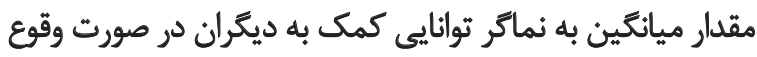

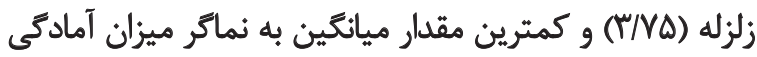

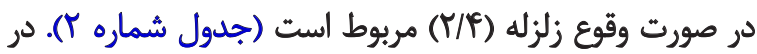

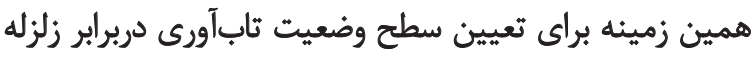

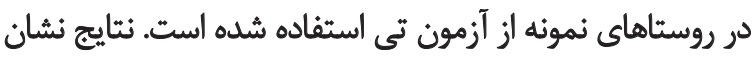

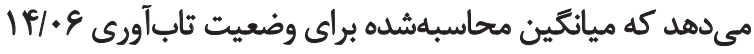

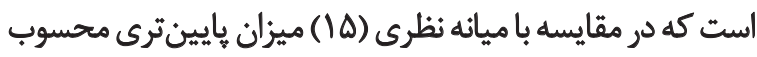

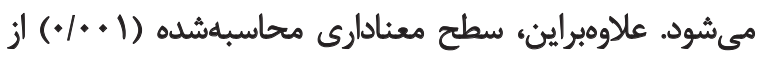

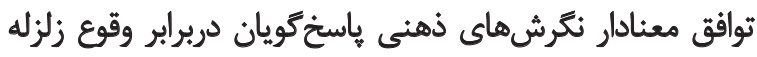

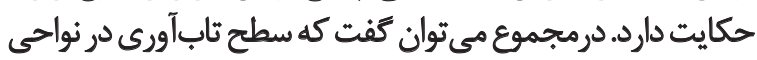

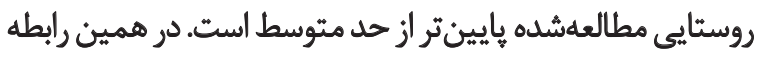

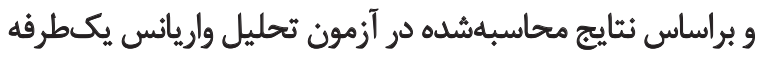

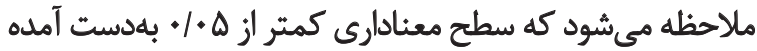

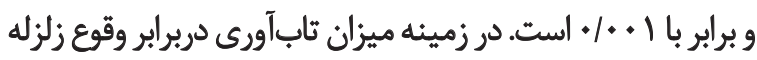

توصيفى تحليلى است. براى جمع آورى اطلاعات لازم از دو روش

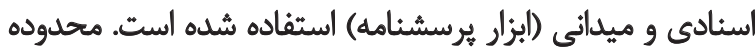

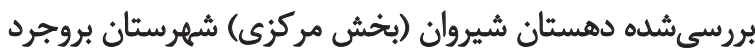

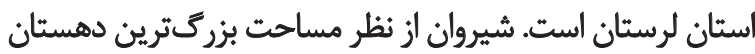

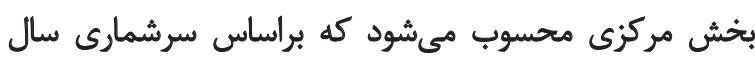

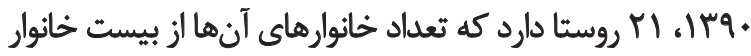

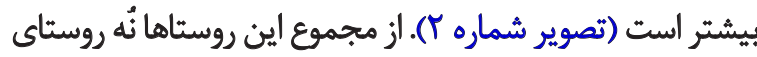

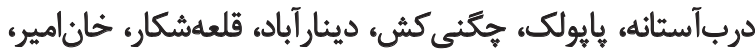

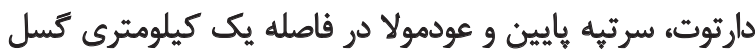

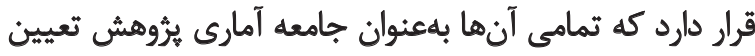

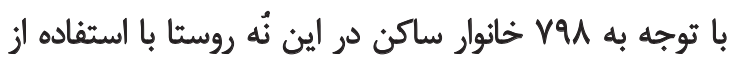

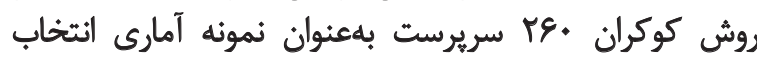

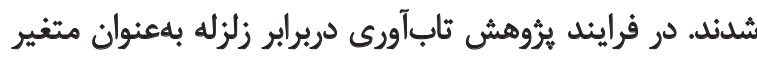

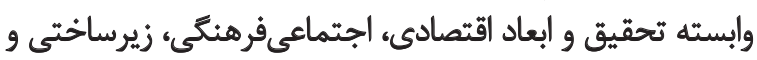

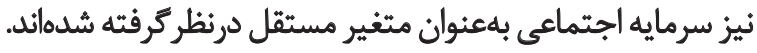

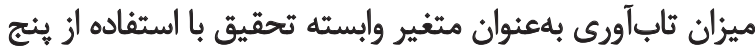

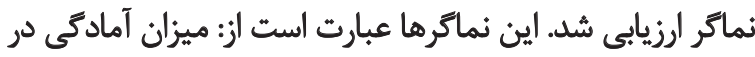

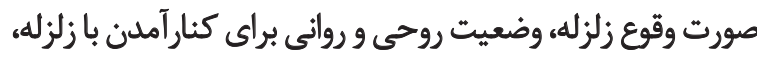

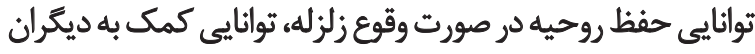

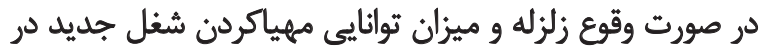

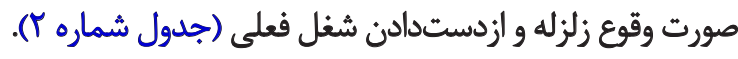
همجنين تعداد نماكرهاى استفادهده براى سنجش وضعيت

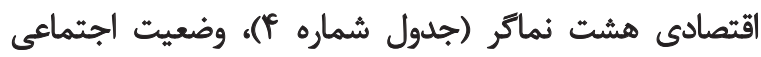

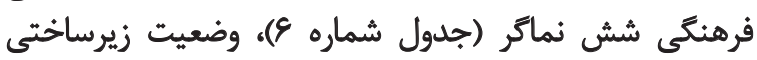

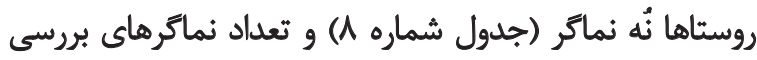

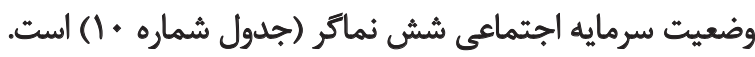

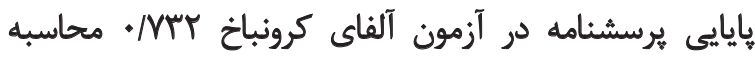

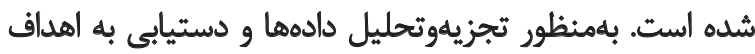


جدول ا.ويثرّى هاي ياسختويان.

\begin{tabular}{|c|c|c|c|}
\hline درصد & تعداد & \multicolumn{2}{|c|}{ ويزَّى } \\
\hline $9 \Delta$ & TEV & مرد & \multirow[b]{2}{*}{ جثس } \\
\hline$\Delta$ & ir & & \\
\hline$M / r$ & Af & ابتدايي & \multirow{4}{*}{ تحصيلات } \\
\hline$m / \Delta$ & AV & راهنمايى & \\
\hline$r+/ e$ & va & متوسطه & \\
\hline$r / \Lambda$ & 1. & ليسانس و بالاتر & \\
\hline$\varepsilon r / \Gamma$ & IET & كشاورز و دامدار & \multirow{3}{*}{ شغل } \\
\hline גות & $M$ & خدمات & \\
\hline$r / \Lambda$ & 1. & ادارى & \\
\hline
\end{tabular}

\begin{tabular}{|c|c|c|c|}
\hline بيشتر از +. لهزار & 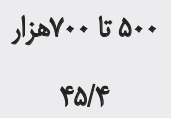 & كمتر از •.هرهزار & درآمد (درصد) \\
\hline & PNF & & هتوسط سن \\
\hline & $\Delta / \Delta$ & & متوسط تعداد خاثوار \\
\hline
\end{tabular}

برايناساس ملاحظه مي شود كه وضعيت اقتصادى در روستاهاى

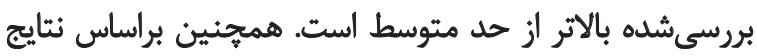

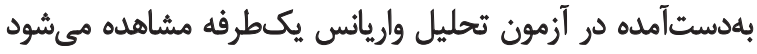

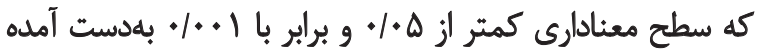

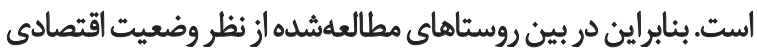

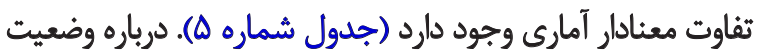

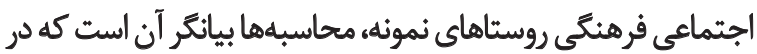

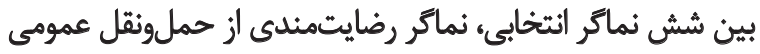

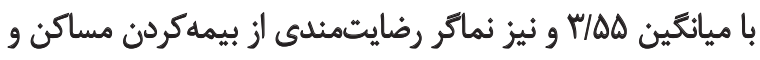

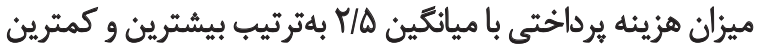

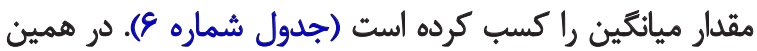

تفاوت معنادار آمارى در ميان روستاهاي بروسي شده وجود دارد

$$
\text { (جدول شماره م) (1). }
$$

بلمنظور بررسى وضعيت اقتصادى در روستاهاى نمونه، 1 نماكر

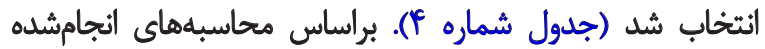

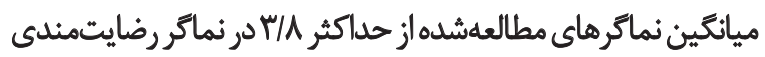

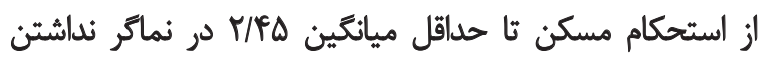

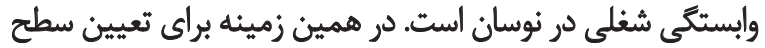

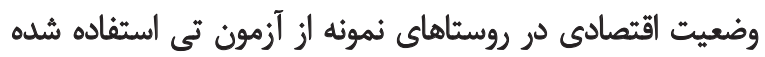

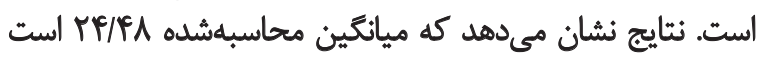

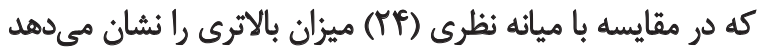

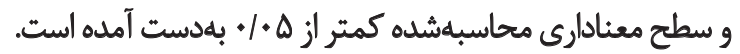

جدول r. ياقتههاى توصيفى مربوط به وضعيت تابآورى دربرابر زلزله.

\begin{tabular}{|c|c|c|c|c|c|c|}
\hline ميائكين & خيلى زياد & زياد & متوسط & كي & خيلى كم & ثماتر \\
\hline$r / f$ & $11 / \Delta$ & $\Delta / \Lambda$ & $r M / 1$ & $r \cdot / 1$ & rNA & ميزان آمادكى در صورت وقوع زلزله \\
\hline$r / \Lambda$ & $1 / \Delta$ & $r \Delta / F$ & $\pi / \Delta$ & $\mathrm{rIT}$ & NA & وضعيت روحى و روانى براى كنارآملن با زلزله \\
\hline$r / u$ & $\Delta / \lambda$ & $r q / 8$ & $r V / Y$ & $r \cdot / \Lambda$ & $9 / \pi$ & توانايى حفظ روحيه در صورت وقوع زلزله \\
\hline$r / V Q$ & $r \Delta / \wedge$ & $r A / F$ & $\| T / K$ & $11 / 9$ & $\varphi / 8$ & توانايى كمك به ديكران در صورت وقوع زلزله \\
\hline$r / M$ & $r / \Lambda$ & $q / r$ & $I T / Y$ & $\mathrm{HT} / \mathrm{\Delta}$ & $r+/ \Lambda$ & ميزان توانايي مهياكردن شغل جليد در صورت وقوع زلزله و ازدستدادن شغل فعلى \\
\hline
\end{tabular}


جدول ت. تحليل سطح تابآورى روستاهاي بررسى شده دربرابر زلزله براساس آزمون تى تكنمونهاى و تحليل واريانس.

نتايج أزمون تى تكنمونهاي

\begin{tabular}{cccccc}
\hline \multicolumn{7}{c}{} & \\
\hline \\
\hline
\end{tabular}

جدول F. يافتهاى توصيفى مربوط به وضعيت اقتصادى ثاب آورى دربرابر زلزله.

\begin{tabular}{|c|c|c|c|c|c|c|}
\hline 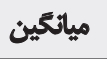 & خيلى زياد & زياد & متوسط & Sم & 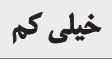 & نماكر \\
\hline$r / \Lambda$ & ra & q. & $4 / r$ & $9 / \pi$ & $p / 8$ & رضايتمندى از استحكام مسكن \\
\hline $4 / .9$ & 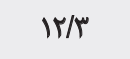 & $r+/ \Lambda$ & $r \Delta / \Lambda$ & $r \& / T$ & $\Delta$ & آكاهى از كميت و كيفيت مسكن \\
\hline$M / M T$ & 1. & ra & YNI & $r M / \Delta$ & $\Delta / \digamma$ & رضايتمندى أز كاركرد مسكن \\
\hline$r / \cdot r$ & $\mid \Delta / F$ & TNI & WN & $19 / 8$ & $|W|$ & رضايتمندى از آيثده شغلى \\
\hline$T / \Delta \Delta$ & $\mathbb{m} / 1$ & $8 / 9$ & $1 \% / \pi$ & $\Delta H / \Lambda$ & $11 / 9$ & بروزنكردن مشكل و اختلالل در فعاليت شغلى در صورت وقوع زلزله \\
\hline$T / R Q$ & $1 \% / \Delta$ & $11 / \Delta$ & $\Delta / r^{e}$ & 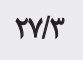 & $r r / T$ & نداشتن وابستكى به يك شغل \\
\hline ו & $m / 1$ & $i f / r$ & $p e / 8$ & $V / r$ & $1 . / 1$ & وضعيث برابرى درآمدى بين اقشار مختلف روستا \\
\hline 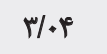 & $9 / \Delta$ & $r \Delta / \digamma$ & $r+/ e$ & $\mathrm{r} / \mathrm{\Delta}$ & $s / r$ & ميزان رضايت از درآمد شخصى خود \\
\hline
\end{tabular}

جدول ه. تحليل وضعيت اقتصادى تابآورى روستاهاى بررسي شده دربرابر زلزله براساس آزمون تي تكنمونهاى و تحليل واريانس. نتايج آزمون تى تكنمونهاى

\begin{tabular}{|c|c|c|c|c|c|c|c|}
\hline \multicolumn{8}{|c|}{ نتايج آزمون تى تكـمونهاى } \\
\hline \multicolumn{2}{|c|}{ فاصله اطمينان ور سطح هو درصد } & \multirow{2}{*}{ سطح معنادارى } & \multirow{2}{*}{ 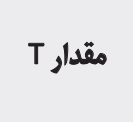 } & \multirow{2}{*}{ استاندارد } & \multirow{2}{*}{ انحراف } & \multirow{2}{*}{ نظرى مياتكين } & \multirow{2}{*}{ مياتعين } \\
\hline بيشترين & كمترين & & & & & & \\
\hline$\cdot / N E \cdot r$ & . & $.1+10$ & r/ppqq & ./194 & $r / \| r$ & rp & re/ra \\
\hline \multicolumn{8}{|c|}{ تحليل تفاوت تابآورى در روستاهاي ثمونه براساس آزمون تحليل واريانس يكطرفه } \\
\hline \multicolumn{2}{|c|}{ 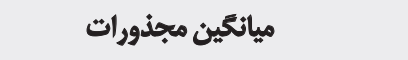 } & \multicolumn{2}{|c|}{ جمع مجذورات } & \multirow{2}{*}{\multicolumn{2}{|c|}{ 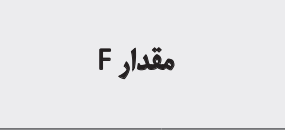 }} & \multirow{2}{*}{\multicolumn{2}{|c|}{ سطح معنادارى }} \\
\hline درون مروهى & بين بروهى & درون كروهى & بينكّروهى & & & & \\
\hline NOIE & $\Delta V / 914$ & $\mathrm{rITV} / \Delta \Delta \Lambda$ & $F / d / r+f$ & & & & \\
\hline
\end{tabular}


جدول و. يافتهاي توصيفى مربوط به وضعيت اجتماعى فرهنكي تابآورى دربرابر زلزله.

\begin{tabular}{|c|c|c|c|c|c|c|}
\hline 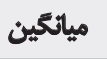 & خيلى زياد & زياد & تاحدودى & S & خيلى كيم & 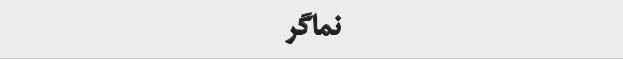 \\
\hline$r / \Delta \Delta$ & r. & $r e / q$ & To & $18 / A$ & $Y / r$ & رضايثمندى از حملونقل عمومى \\
\hline$r / T \Delta$ & $1 \% / 0$ & $\pi / \Lambda$ & $\mathbb{R T / N}$ & $11 / 9$ & $\Delta$ & ميزان رضايتمندى از شبكه ارتباطات ماثند ثلفن و ثلفن اضطرارى \\
\hline$r / R$ & $9 / 8$ & $18 / 9$ & $r V / r$ & 1. & $9 / \pi$ & ميزان سلامت جسمى شما \\
\hline$r / p q$ & $\mid f / 8$ & fo & $r \Delta / f$ & $\Delta / f^{e}$ & $9 / 8$ & ميزان سلامت روحى و روانى شما \\
\hline$r / 1$ & $V / V$ & YNI & $\pi / \Gamma$ & $r \cdot / \varphi$ & $1 / \Delta$ & ميزان رضايتمندى از دسترسى به هيزشى \\
\hline$r / \Delta$ & $\mid f / r$ & $19 / 9$ & $\Delta / \Lambda$ & $r+/ \Lambda$ & $M T /{ }^{\prime}$ & رضايتمندى از بيمهكردن مساكن و ميزان هزينه يرداختى \\
\hline
\end{tabular}

جدول V. تحليل وضعيت اجتماعى فرهنكى تابآورى روستاهاى مطالعهشده دربرابر زلزله براساس آزمون تى تكنمونهاى و تحليل واريانس.

ثتايج أزمون تي تكـنمونهاى

\begin{tabular}{|c|c|c|c|c|c|c|c|}
\hline \multicolumn{8}{|c|}{ تنايج آزمون تى تكنمونهاى } \\
\hline \multicolumn{2}{|c|}{ فاصله اطمينان در سطح هو درصد } & \multirow{2}{*}{ سطح معنادارى } & \multirow{2}{*}{ مقدار تى } & \multirow{2}{*}{ خطاي استاندارد } & \multirow{2}{*}{ انحراف } & \multirow{2}{*}{ نظري ميأكين } & \multirow{2}{*}{ مياتكين } \\
\hline بيشترين & كمترين & & & & & & \\
\hline V/AAT & $1 / P A$ & $.1 . .1$ & $V / 1 \cdot r$ & $\cdot M \cdot F$ & $r / r q 1$ & $M$ & $19 / 70$ \\
\hline \multicolumn{8}{|c|}{ تحليل تفاوت تابآورى در روستاهاي نمونه براساس آزمون تحليل وأريانس يكطرفه } \\
\hline \multicolumn{2}{|c|}{ ميانعُين مجذورات } & \multicolumn{2}{|c|}{ جمع معزدورات } & \multirow{2}{*}{\multicolumn{2}{|c|}{ 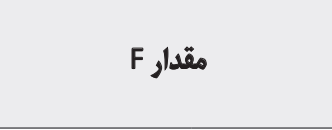 }} & \multirow{2}{*}{\multicolumn{2}{|c|}{ سطح معنادارى }} \\
\hline درون كروهى & بين ئروهى & 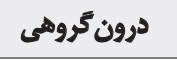 & بين مَروهى & & & & \\
\hline$\Delta / r \forall \wedge$ & $\mid A T / \cdot \Delta F$ & $1 m+q / q .1$ & IFAF/RFq & $\mathrm{r} / \mathrm{N} \Delta$ & & & \\
\hline
\end{tabular}

جدول A. يافتههاى توصيفي مربوط به وضعيت زيرساختى تابآورى دربرابر زلزاله.

\begin{tabular}{|c|c|c|c|c|c|c|}
\hline مياتكين & خيلى زياد & زياد & ت تاحدودى & كمي & خيلى كم - & 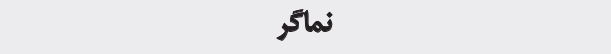 \\
\hline r/A" & $11 / 0$ & $\pi / \Delta$ & $r M / r$ & $m / r$ & $\sqrt[9]{8}$ & ميزان رضايتمندى از كيفيت و كميت راههاى ارتباطى \\
\hline$r / \bullet 1$ & $11 / \%$ & $r M / r$ & 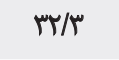 & $r e / 9$ & NI & ميزان رضايتمندى از دسترسى به بيمارستان در زمان وقوع زلزٔله \\
\hline$r / M$ & $M / \Lambda$ & $r \& / 0$ & $10 / 4$ & $r / r$ & $11 / 9$ & برخوردارى روستاهاي منطقه از آب لوله كشى \\
\hline $4 / .9$ & rNA & $m+1 /$ & $\cdot / \Lambda$ & $\Delta / f^{\digamma}$ & $9 / \pi$ & برخوردارى روستاهاى منطقه از شبكه برق مناسب \\
\hline r/st & $r e / r$ & $m / \lambda$ & $r+/ \Lambda$ & $\mid f / r$ & Q & دسترسى به مراكز أموزشى مدارس، مهلكودك، دانشكاه و... \\
\hline$t / 4 t$ & $\mathrm{~V} / \mathrm{r}^{\mu}$ & $18 / \lambda$ & $19 / 0$ & $I T / Y$ & $P V / V$ & دسترسى به نهادهاى امدادرسان، مركز مديريت بحران و... \\
\hline$r / 11$ & $\mid r / r$ & 10 & $\varphi g / 9$ & $r \pi / \Delta$ & $r / r$ & دسترسى به يليس و نيروى انتظامى \\
\hline$V / \Delta$ & $1 / \Delta$ & $r / \Delta$ & $\Delta / T^{+}$ & $r m / 1$ & $99 / \Delta$ & دسترسى به آتش نشانى \\
\hline$r / \% \Delta$ & $11 / 0$ & $\Delta / / \Delta$ & ND & $r / q$ & $1 / \Delta$ & دسترسى به شبكه معابر اصلى \\
\hline
\end{tabular}


جدول 9.

$$
\text { نتايج آزمون تى تكنمونداى }
$$

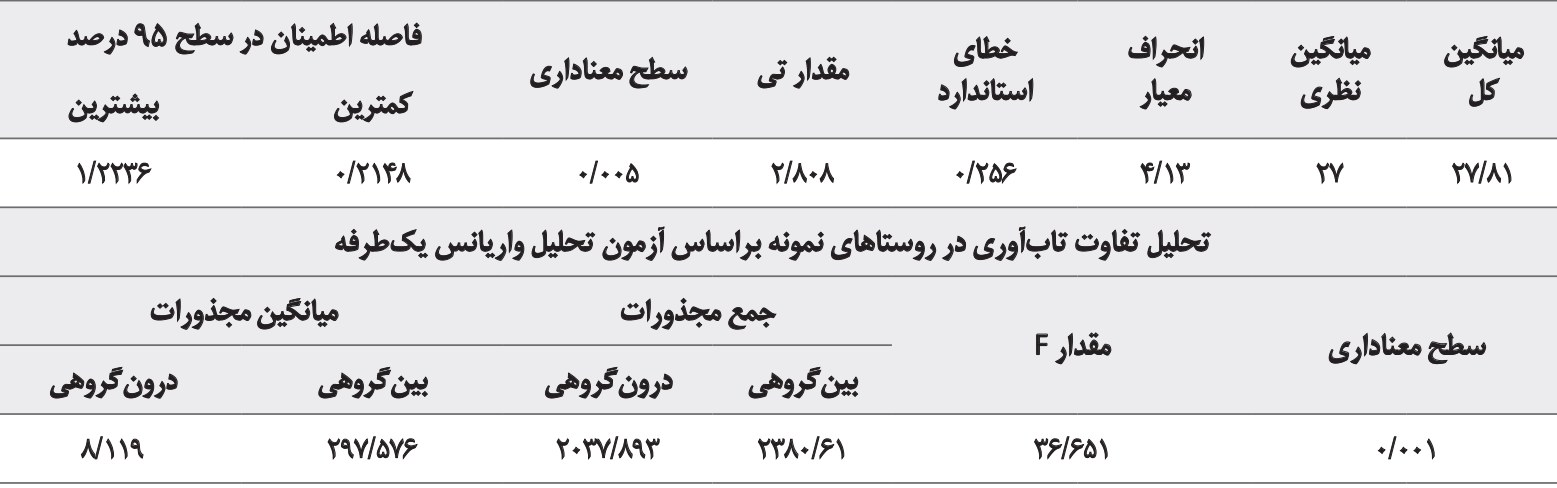

زمينه نتايج بهدستآمده از آزمون آمارى تى تكنمونهاى نشان از

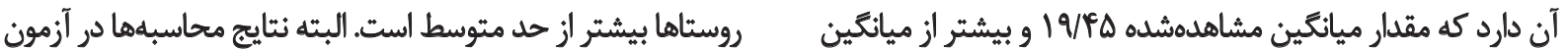

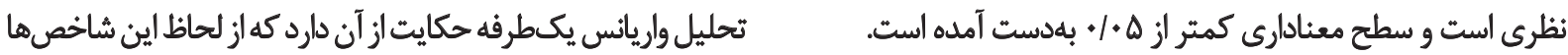

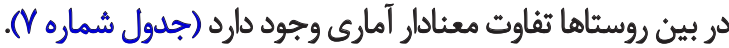

جدول •ا. يافتههاى توصيفى مربوط به سرمايه اجتماعى تابآورى دربرابر زلزله.

\begin{tabular}{|c|c|c|c|c|c|c|}
\hline 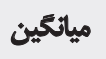 & خِيلي زياد & زياد & تاحدودى & Sم & خيلى كم & نماكر \\
\hline T/Tq & $\Delta \Delta / \Lambda$ & $r / r$ & $1 / 8$ & $m / 1$ & $\Delta / f^{e}$ & ماندكارى در روسئا \\
\hline f & $p e / \&$ & $M T / V$ & $V / \mu$ & $N A$ & $8 / \Delta$ & ميزان همبستكى يين مردم در صورت وقوع زلزله \\
\hline$m / q u$ & $\Delta T / T$ & TI/Q & $\Delta$ & $r / q$ & $11 / 9$ & جشميوشى از منافع شخصى براى رعايت مصالح جامعه \\
\hline$r / M r$ & $r q / r$ & $r \& / \Delta$ & 1. & $18 / \pi$ & $N 1$ & كمك به مديران محلى در اثر وقوع زلزله \\
\hline$r / \Delta Y$ & $r / r$ & $r M / r$ & $r g / \Delta$ & 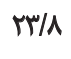 & 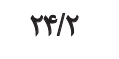 & تمايل به عضويت و فعاليت در شوراو دهيارى \\
\hline א ג & $\Delta / \Lambda$ & $r / 8$ & TrT & $\mathrm{H} / \mathrm{Q}$ & $r+/ \Lambda$ & مشاركت ميان جوامع، بخش خصوصى و مقامهاى محلى براى كاهش \\
\hline
\end{tabular}

ثتايج أزمون تى تكنمونداى

\begin{tabular}{|c|c|c|c|c|c|c|c|}
\hline \multicolumn{8}{|c|}{ نتايج آزمون تي تكنمونهاي } \\
\hline \multicolumn{2}{|c|}{ فاصله اطمينان در سطح هو درصد } & \multirow{2}{*}{ سطح معنادارى } & \multirow{2}{*}{ 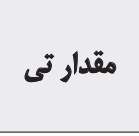 } & \multirow{2}{*}{ استاندارد } & \multirow{2}{*}{ اتحعراف } & \multirow{2}{*}{ نظياتكين } & \multirow{2}{*}{ مياكَين } \\
\hline بيشترين & كمترين & & & & & & \\
\hline$r / F V$ & 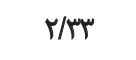 & $.1 .+1$ & $9 / 419$ &.$/$ rq. & $H / F \Lambda$ & M & $r+/ q$ \\
\hline \multicolumn{8}{|c|}{ تحليل تفاوت تابآورى در روسثاهاى نمونه براساس أزمون تحليل واريانس يكىطرفه } \\
\hline \multicolumn{2}{|c|}{ مياتكين مجذورات } & \multicolumn{2}{|c|}{ جمع مجذورات } & \multirow{2}{*}{\multicolumn{2}{|c|}{ 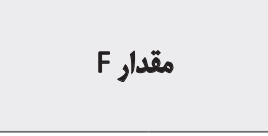 }} & \multirow{2}{*}{\multicolumn{2}{|c|}{ سطح معنادارى }} \\
\hline دون مكروهى & بين كروهى & درون كروهى & بين كروهى & & & & \\
\hline$\Delta / \Delta V Y$ & $\Delta M e / g .8$ & IrWAPq & PTVE/AOI & \multicolumn{2}{|c|}{ १Q/१९V } & \multicolumn{2}{|c|}{$.1 . .1$} \\
\hline
\end{tabular}


جدول rا. تحليل رابطه ميزان تابآورى با وضعيت اقتصادى و اجتماعىفرهنكى و زيرساختى روستاها.

\begin{tabular}{|c|c|c|}
\hline \multicolumn{3}{|c|}{ ميزان تابآورى دربرابر مخاطرات طييعى با تأكيد بر زلزله } \\
\hline . $M T H$ & ميزان همبستكى & \multirow{2}{*}{ وضعيت اقتصادى } \\
\hline$+1+\infty 1$ & سطح معنادارى & \\
\hline.$/ \Delta 1 Y$ & ميزان همبستكى & \multirow{2}{*}{ وضعيت اجتماعي قرهنكى } \\
\hline .1 .01 & سطح معنادارى & \\
\hline.$/ 194$ & ميزان هبستكى & \multirow{2}{*}{ وضعيت زيرساختى } \\
\hline .1 .04 & سطح معناداري & \\
\hline - Ienf & ميزان همبستكى & \multirow{2}{*}{ سرمايه اجتماعي } \\
\hline$+1++1$ & سطح معنادارى & \\
\hline
\end{tabular}

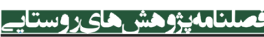

جدول سا. تأثير ابعاد مطالعهشده در ميزان تابآورى دربرابر زلزله.

\begin{tabular}{|c|c|c|c|}
\hline سطح معادارى & مقدار بتا & مقدار تى & بعد \\
\hline $.1 .+1$ &.$M I E$ & $4 \% 19$ & وضعيت اجتماعىفرهنكي \\
\hline .1 .90 & $.1+\Delta r$ & V/NAF & وضعيت اقتصادى \\
\hline $.1 \cdot \pi$ &.$/ 1.4$ & $r / M F$ & وضعيت زيرساختى \\
\hline $.1 \cdot+1$ &.$/ \Delta \Lambda$ & IH/ITH & سرمايه اجتماعي \\
\hline
\end{tabular}

انجامشده در بين نماكر هاء بيشترين و كمترين مقدار ميانئين

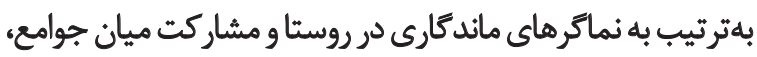

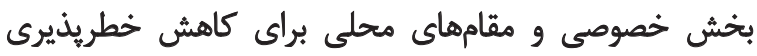

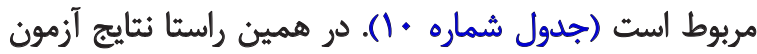

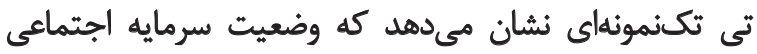

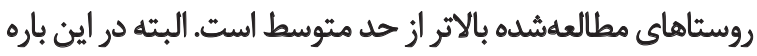

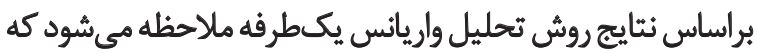

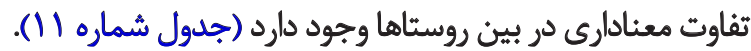
بهمنظور بررسى رابطه بين ميزان تابآورى دربرابر زلزله و وإئه

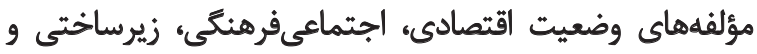

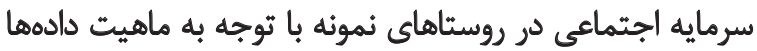

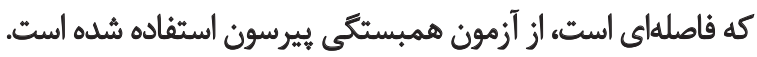

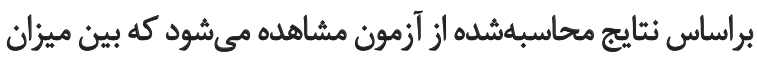

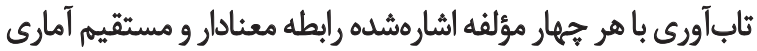

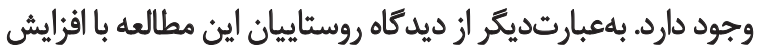

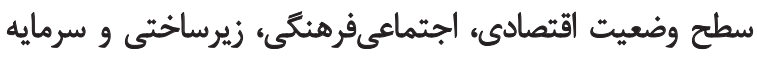

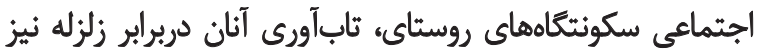

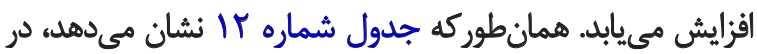

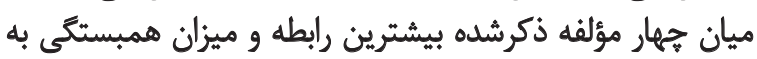

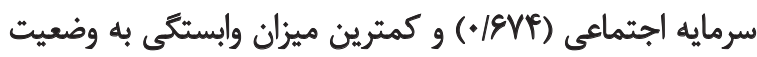

برربي و تحليل نماكرهاي مربوط به سنجش سطح وضعيث

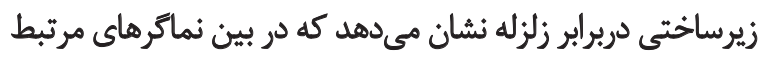

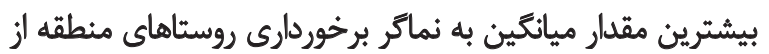

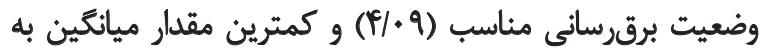

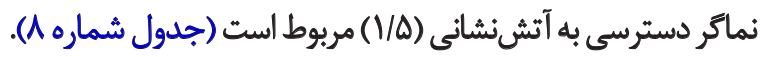

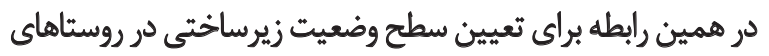

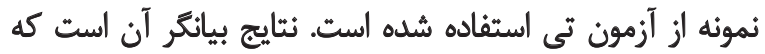

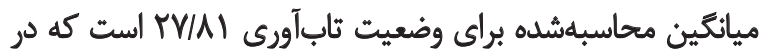

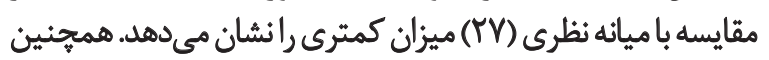

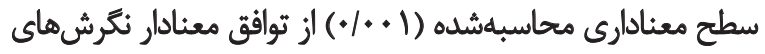

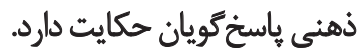

درمجموع مىتوان كفت سطح وضعيت زيرساختى در نواحى

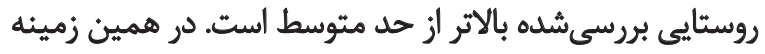

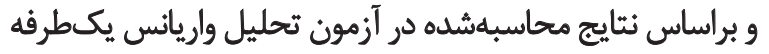

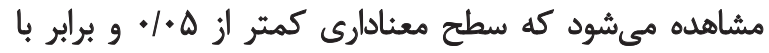

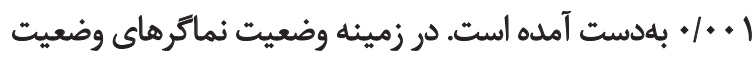

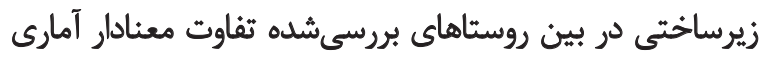
وجود دارد (جدول شماره 9).

بلهمنظور بررسى وضعيت سرمايه اجتماعى در روستاهاي نمونه، ع نماكر انتخاب شد (جدول شماره ff). براساس محاسبهمائي 
زيرساختى رابطه معنادار آمارى مستقيم وجود دارد. بهعبارتديكر

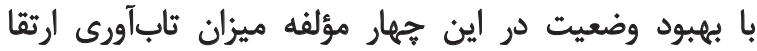

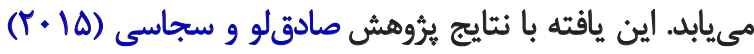

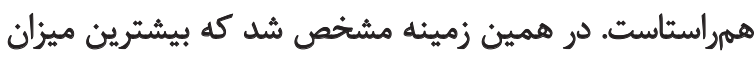

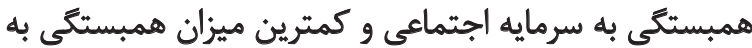
وضعيت زيرساختى روستاها مربوط بود.

درمجموع با توجه به نتايج بهدست آمده، بيشنهادهاى زير ارائه مى شود: 1. افزايش سطح آكاهى ساكنان نواحى روسثايى؛

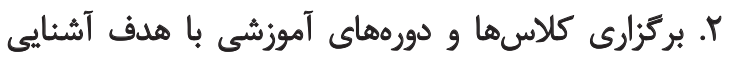

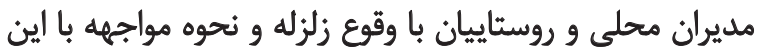

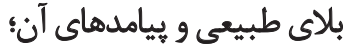
"ا. مشاركت روستاييان در طرحها و برنامههاي مختلف در اين لين زمينه؛

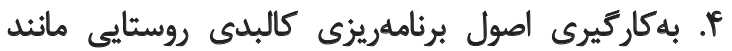

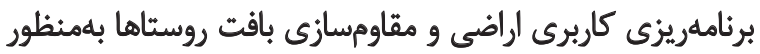

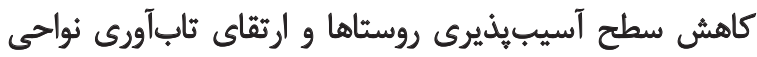
روستايى دربرابر زلزله. - ماني

$$
\text { زيرساختى (بو/|•) مربوط است. }
$$

از ديكر اهداف اين يُوهش، بروسى تأثير هريك از ابعاد

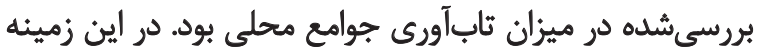

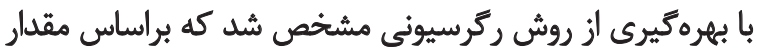

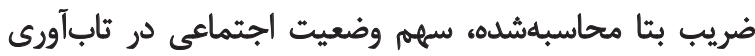

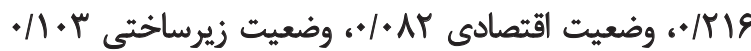

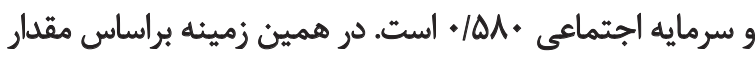

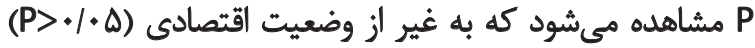

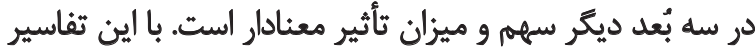

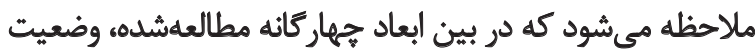

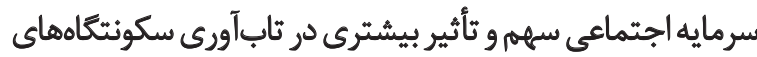

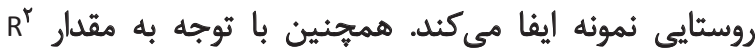

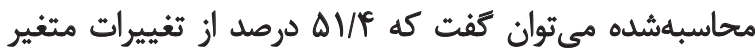

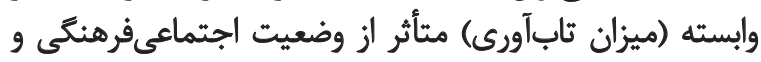

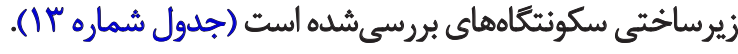

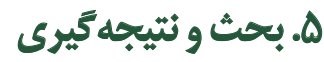

مخاطرات طبيعى بلهنوان بديدههاى مخرب طبيعى در مرحله

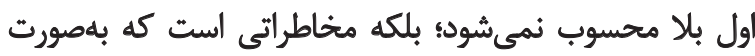

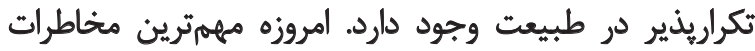

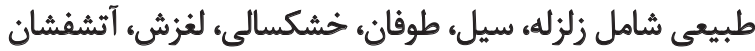

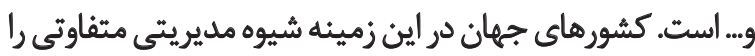

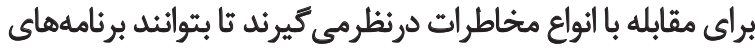

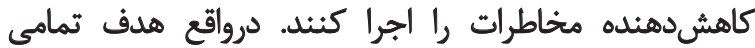

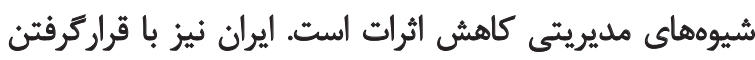

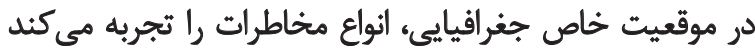

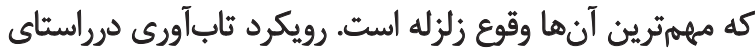

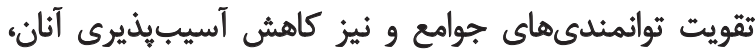

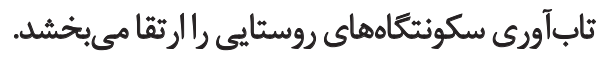

در اين يرؤهش وضعيت تابآٓورى جوامع روستايى دهستان

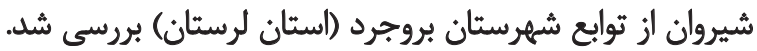

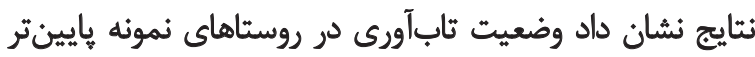

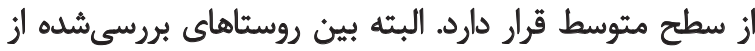

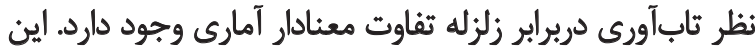

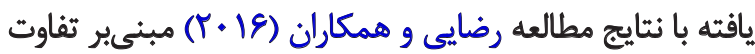

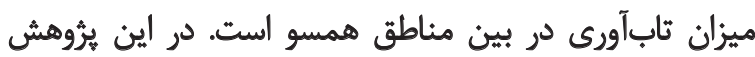

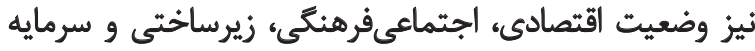

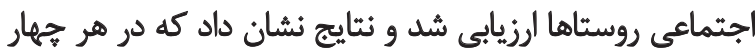

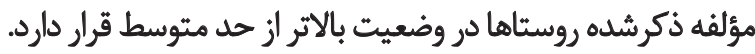
همان طوركه در مبانى نظرى بدان اشاره شده عوامل و مؤلفههاى

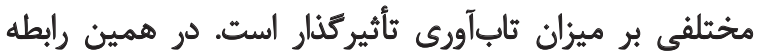

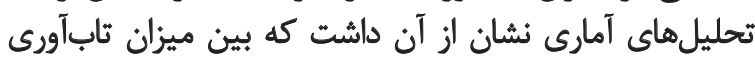
با وضعيت اقتصادى، اجتماعىفرهنگي، سرمايه اجتماعى و نيز انيز 


\section{References}

Ainuddin, S., \& Routray, J. K. (2012a). Community resilience framework for an earthquake prone area in Baluchistan. International Journal of Disaster Risk Reduction, 2(1), 25-36.

Ainuddin, S., \& Routray, J. K. (2012b). Earthquake hazards and community resilience in Baluchistan. Natural Hazards, 63(2), 909-37.

Babakhani, F., Yazdannasab, M., \& Nouri, M. (2013). [Important influential factors on people's tendency for voluntary participation during crisis (Persian)]. Journal of Emergency Management, 2(2), 5-13.

Badri, S. A., Ramezanzadeh Lasbooi, M., Asgari, A., Ghadiri Masoum., M., \& Salmani, M. (2013). [The role of local management in improving resilience to natural disasters with emphasis on floods (Persian)]. Journal of Emergency Management, 2(3), 37-48.

Bruneau, M., Chang, S. E., Eguchi, R. T., Lee, G. C., O'Rourke, T. D., Reinhorn, A. M., et al. (2003). A framework to quantitatively assess and enhance the seismic resilience of communities. Earthquake Spectra, 19(4), 733-52.

Cutter, S. L., Barnes, L., Berry, M., Burton, C., Evans, E., Tate, E., et al. (2008). A place-based model for understanding community resilience to natural disasters. Global Environmental Change, 18(4), 598-606.

Eftekhari, A. R., Mosavi, S. M., Poortaheri, M., \& Farajzadeh, M. (2014). [Analysis of the role of livelihood diversity to rural household resilience in drought condition: case study of the drought exposed areas of Isfahan province (Persian)]. Journal of Rural Research, 5(3), 476-704

Eynali, J., Farahani, H., \& Jafari, N. (2014). [Evaluation of the role of social capital in reduction of earthquake disaster consequences in Sojasrood county Khodabande township (Persian)]. Journal of Applied Researchs in Geographical Sciences, 14(32), 93-115.

Gaillard, J. C. (2007). Resilience of traditional societies in facing natural hazards. Disaster Prevention and Management, 16(4), 522-44.

Gaillard, J. C., \& Texier, P. (2010). Religions, natural hazards, and disasters: an introduction. Religion, 40(2), 81-84.

Hamilton, R. M., Andrews, R. A., Bauer, R. A., Bullock, J. A., Chang, S. E., Holmes, W. T., et al. (2011). National earthquake resilience: research, implementation, and outreach. Washington, D.C.: National Academies Press.

Kafle, S. K. (2012). Measuring disaster-resilient communities: a case study of coastal communities in Indonesia. Journal of Business Continuity \& Emergency Planning, 5(4), 316-26.

Paton, D., \& Johnston, D. (2001). Disasters and communities: vulnerability, resilience and preparedness. Disaster Prevention and Management, 10(4), 270-77.

Petak, W. (2002). Earthquake resilience through mitigation: a system approach. Paper presented at the International Institute for Applied Systems Analysis, 12 Sep 2002, Laxenburg, Austria.

Rafieh, Z., Zare, M., Gheitanchi, M. R., \& Maleki, Z. (2011). [Seismic zonation and potential analysis of Lorestan province (Persian)]. Quarterly Journal of the Earth, 6(19), 51-63.

Rafieian, M., \& Motahhari, Z. (2012). [Designing model for study approach of community-based disaster risk management; Case study DAVAM Plan (Persian)]. Journal of Emergency Management, $1(1), 5-12$.
Rafieian, M., Rezaei, M. R., Askari, A., Parhizkar A., \& Shayan, S. (2011). [Explaining the concept of resilience index of communitybased disaster management (CBDM) (Persian)]. Journal of Spatial Planning, 15(4), 19-41.

Ramezanzadeh Lasbooi, M., (2008). [The role of financial participation in flood risk management in rural areas: watershed Tyrom (Persian)] (MA thesis). Tehran: Tehran University.

Ramezanzadeh Lasbooi, M., Badri, S. A., Asgari, A., Salmani, M., \& Ghadiri Masom, M. (2013). [Rural resilience sample tourism regions on multiple attribute decision making (Case study: Cheshmeh Kileh branch, Tonekabon county and Sardabrood branch, Kelardasht county) (Persian)]. Journal of Tourism Planning and Development, 1(3), 131-55.

Rezaei, M. R., Rafieian, M., \& Hosseini, S. M. (2016). Assessment of urban physical resilience against earthquakes (Persian)]. Human Geography Research, 47(4), 609-23.

Ride, A. (2011). Community resilience in natural disasters. New York: Palgrave Macmillan.

Rose, A. (2007). Economic resilience to natural and man-made disasters: multidisciplinary origins and contextual dimensions. Environmental Hazards, 7(4), 383-98.

Rutter, M. (1999). Resilience concepts and findings: implications for family therapy. Journal of Family Therapy, 21(2), 119-44. doi: 10.1111/1467-6427.00108

Sadeghloo, T., \& Sojasi, H. (2015). [Survey relationship between rural settlement livability and rural resilience in front of natural disaster in rural areas of Mravehtapeh and Palizan county (Persian)]. Journal of Emergency Management, 3(2), 37-44.

Salehi, E., Aghababaei, M. T., Sarmadi, H., \& Farzad Behtish, M. R. (2011). [Considering the environment resiliency by use of cause model (Persian)]. Journal of Environmental Studies, 37(59), 99-112.

Sharifnia, F. (2012). [Investigating the relationship between urban land use and the resiliency of the earthquake and solutions in the field of urban planning; Case study: Tehran, Region 1 (Persian)] (MA thesis). Tehran: Tehran University.

Walker, B., Holling, C. S., Carpenter, S. R., \& Kinzig, A. (2004). Resilience, adaptability and transformability in social-ecological systems. Ecology and Society, 9(2), 5. Retrieved from http:/ / www. ecologyandsociety.org/vol9/iss2/art5 